\title{
Unified Field Theory and Foundation of Physics
}

\author{
Zhiliang Cao ${ }^{1,2, *}$, Henry Gu Cao ${ }^{3}$ \\ ${ }^{1}$ Wayne State University, $42 \mathrm{~W}$ Warren Ave, Detroit \\ ${ }^{2}$ Shanghai Jiaotong University, Shanghai, China \\ ${ }^{3}$ Northwestern University, Evanston, IL 60208, USA \\ *Corresponding author: williamcao12252000@yahoo.com
}

Received September 09, 2014; Revised September 20, 2014; Accepted September 25, 2014

\begin{abstract}
The paper "Unified field theory" (UFT) [1] opened a new chapter of physics. The main model of UFT is Torque Grids that unify Space, Time, Energy and Force. The configuration of invisible particles [2] and structure of the grand universe [3] can be logically induced. Visually, the universe can be modeled as single Torque Grids' hierarchy. A simple UDP Java program can be used to prove the space-time-energy-force relationship predicted by the unified field theory and explain why the continents are drifting [4]. One of the applications of UFT is to predict the nuclei topologies [5] of each element. Physics, "knowledge of nature", is defined as a natural science that involves the study of matter and its motion through space and time, along with related concepts such as energy and force. UFT gives a better definition of Physics: "A natural science that involves the study of motion of space-timeenergy-force to explain/predict the motion, interaction and configuration of matter."
\end{abstract}

Keywords: nuclear physics, particle physics, unified field theory, astronomy, GPS, atomic clock

Cite This Article: Zhiliang Cao, and Henry Gu Cao, "Unified Field Theory and Foundation of Physics." International Journal of Physics, vol. 2, no. 5 (2014): 158-164. doi: 10.12691/ijp-2-5-5.

\section{Introduction}

Unified Field Theory (UFT) [1] physically models the world using Torque Grids that are invisible but understandable. As Physics progresses, it focuses more on invisible particles [2] and the unreachable grand universe [3] as visible matter is studied theoretically and experimentally. The old models focus on visible matter, such as particles, and celestial objects. These models limit themselves to tangible things that failed to serve as the fundamental basis of Physics. The Torque Grid model is logical and self-evident. The concept of space, time, energy and force reflected in the model are most fundamental and physical.

UFT covers all levels of physics, from the most basic concept to the most advanced theory. It derives physics equations one by one using space-time-energy-force in the model of Torque Grid. UFT develops the theories firmly on the foundation of space-time-energy-force with help of the Torque Grid model.

The relationship between space and time is described in Relativity; however, UFT claims that space and time are inseparable. Without time, space has no meaning in Physics, since it requires time to measure motion in space. Similarly, without space, time has no Physics meaning, since space is needed to measure motion in time.

Space and time still have no meaning if there are no differentials in space-time. Energy is the differential. In UFT, there is no true void. Energy in space-time is modeled as distortions.
UFT is a study of fields, which represent forces in space. Therefore, force is a fundamental concept in UFT.

Visually, space is modeled as Grids, energy is modeled as strings, time is modeled as light speed twisting movement of strings, and force is modeled as Grids' resistance to the distortion. Finally, the model becomes Torque Grids.

UFT does not try to prove the existence of Torque Grids experimentally and there is no difference between border of the Grid and the internal part of the Grid. Therefore, physical Torque Grids do not exist. Fortunately, even though they are not tangible, they are understandable. Torque Grids model can explain the existing theory and make useful predictions of motion, interaction and configuration of matter.

\section{Torque and Grid}

As a natural science that involves the study of motion of space-time-energy-force, UFT studies arbitrary motion in 3D space and time. The directions of an arbitrary 3D movement are changing and correlated. There are two possible movements, $\mathrm{S}$ twist and $\mathrm{Z}$ twist. Other than twist movements, there are straight line and circular movements as well, but straight line is a $1 \mathrm{D}$ movement and circular movement is a $2 \mathrm{D}$ movement, only the following twists are true 3D movements:

The Twist movements are called Torques. In the Figure 1 , the left image is a tightening Torque, while the one on the right is a loosening Torque. "Tightening" and "Loosening" are the two different directions of Torques. The Torque movement appears in everyday life. For 
example, the act of screwing a lid onto a jar is a "Tightening" Torque. When opening a door with a knob, a Loosening Torque is taking place.

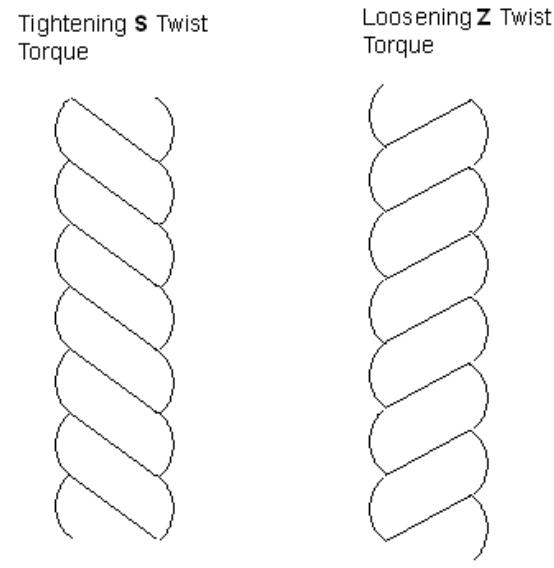

Figure 1. Torques

One can choose three directions in a $3 \mathrm{D}$ coordinate system and use a String unit length to form a cube. A Torque Grid system emerges:

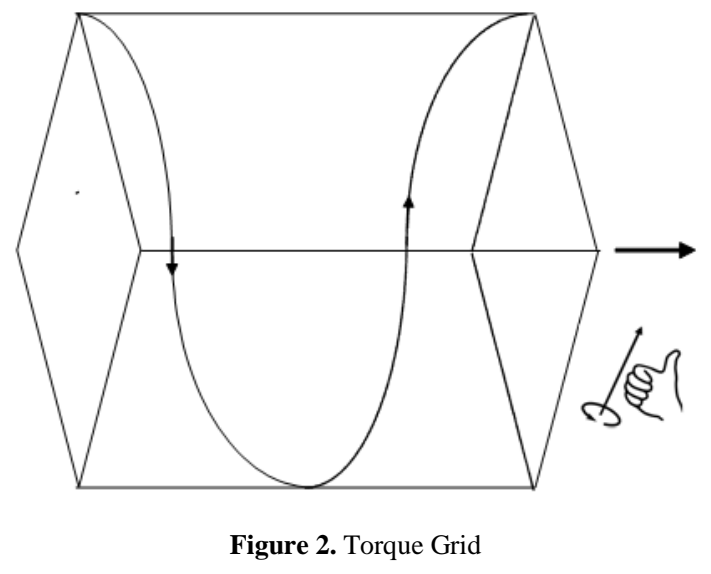

Figure 2 has a single Torque Grid with a single Torque cycle. To make it easier to remember the movement of the Torque String, this theory assumes that the main Torque String movements in the vacuum of the universe are righthanded. Positive charge has right-handed static Torque, while negative charge has left-handed static Torque. The positive and negative charge is result of natural 3D arbitrary motion.

\section{Energy and Gravity}

Torque model for space-time still have no Physics meaning if there are no differentials in space-time. The differentials are energy. Energy is a result of Torque Grids' distortion [1] when space and time are not evenly distributed.

Our previous Clock-Drifting Experiment [4] proved that space and time are not even in the gravity field. The energy is proportional to the stretching and compression of Torque Grids [1] where matter is presented. The energy differences for same matter in space lead to gravity [1]:

$$
\mathrm{F}=\mathrm{mc}^{2} * \mathrm{dD} / \mathrm{ds}
$$

$$
\begin{aligned}
& \mathrm{F}=\mathrm{mc}^{2} *(\mathrm{dD} / \mathrm{c}) /(\mathrm{ds} / \mathrm{c}) \\
& \mathrm{F}=\mathrm{mc}^{2} * \mathrm{dT} / \mathrm{dt}
\end{aligned}
$$

Stretching and compression distortion of Torque Grids do not introduce energy in a vacuum, while the twisting distortion of Torque Grids has energy. Electron-magnetic waves manifest from the twisting distortion of the Torque Grids and they move at same speed as the string of Torque Grids. This is consistent with the Torque Grids model. The energy is related to twisting motions.

\section{Twist of Particle}

Torque Grids' twist distortion is the basic energy form. When a Torque Grids' twist distortion resonates with Torque Grids, the twist distortion stops moving along with the Torque Strings. The twist distortion forms a twist residue. A stable residue with the lowest possible energy has one Torque Grid twist distortion. The residue is an electron (or positron), or unit charge.

The unit charge forces can be calculated based on the above claims.

The other particles [2] are formed as result of the proper energy distortion wave resonance with unit charge.

The mass of a particle can be expressed in a wave formula [2] that can be used to predict the properties of the particle.

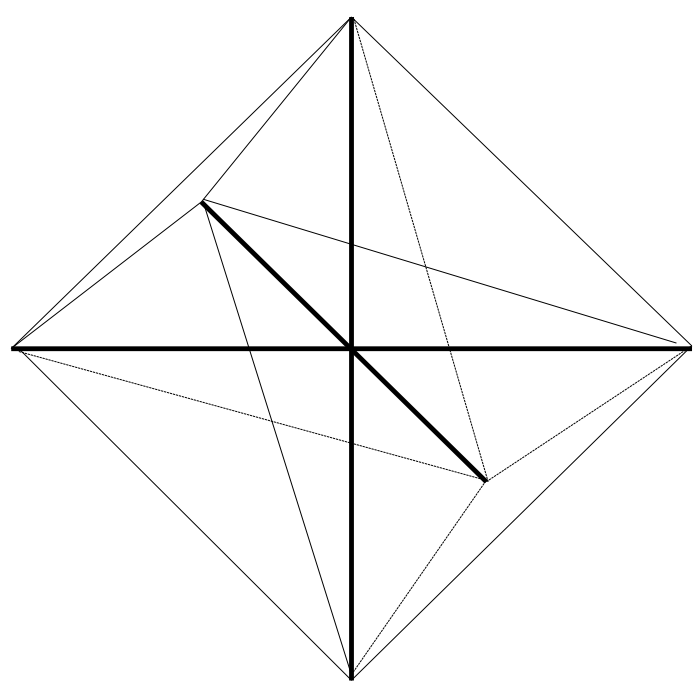

Figure 3. Three Axes Octahedron shape

A proton has an octahedron shape based on its mass formula.

Particle prediction:

The structure of $\mathrm{T} 2$ is:

$2 *(11 * 12 * 13)+23+23+23+0.195=6141.1495$

Or 3138.1208MeV

\section{Unified Fields}

UFT considers gravity and electromagnetic field basic fields. The strong field and weak field are mainly due to the wave formula of the electron:

$$
3 * 5 * 8+3 * 5+2=137
$$

Or, 
A unit charge is composed of waves with masses of 137 times the electron mass. The unit charge can have another resonance condition: The Planck distortion and electronic Torque distortion [2] are both one Torque Grid size. The new distortion becomes a stable wave by itself, the strong force wave.

The Planck distortion on the shell of an electron is 1/137 of Grid size.

The weak interaction energy is the product of the two weak distortions. Therefore, total energy is $(1 / 137) *$ (1/137) of the unit charge energy.

When waves resonate with one another, the weak interaction unit is:

$$
\frac{1}{137 * 137 * \prod_{1}^{n} S_{i}}
$$

When waves are dissonant with one another, the compensate wave interaction unit is:

$$
\frac{\prod_{1}^{x} P_{i}}{\prod_{1}^{y} Q_{i}}
$$

In order to properly predict the mass of the particles, the above additional interactions are needed to give calculation of the particle mass much precise as compared to standard model [8-13].

\section{Hierarchical Universe}

If there is a Torque Grid, then, is there anything inside the Torque Grid? Is there a boundary for our visible universe?

To answer the above questions, UFT logically induced that the universe is hierarchical [3]. It can be infinitely large, or infinitely small in size.

The conclusion is clearly contradicted to the conventional Big Bang Theory (BBT). An experiment [6] is proposed to explain Red Shift of remote galaxies is the result of electron-photon interaction.

Child Grid and parent Grid have different Torque (twisting) directions. Since left and right are relative, each Torque Grid hierarchy shares the same Physics laws.

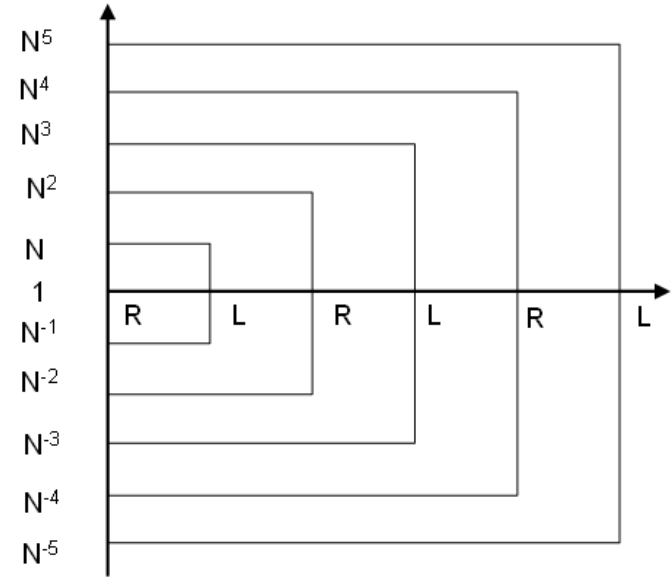

Figure 4. Torque Grid Hierarchy
The hierarchical universe gives us an insight regarding how things are related since there is a single universe modeled as Torque Grids which is deeply rooted in the ancient ideology:

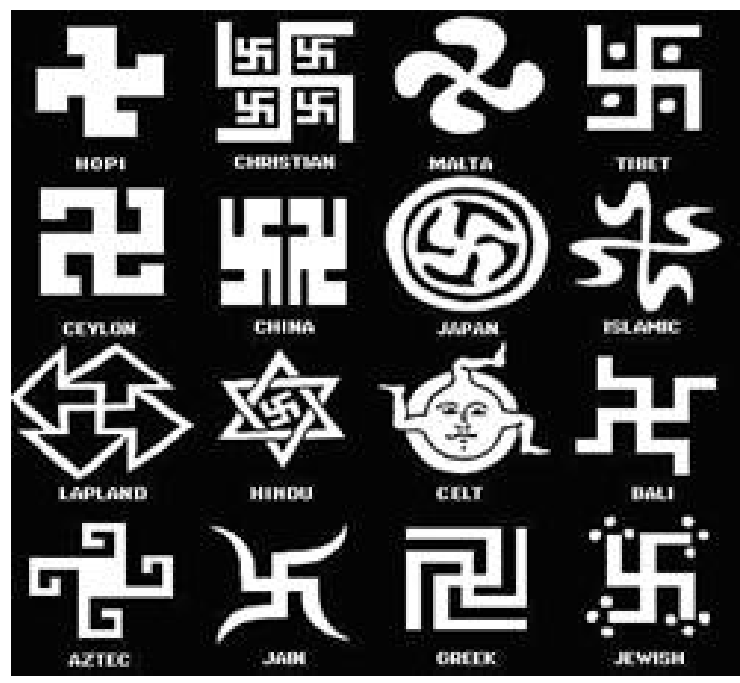

Figure 5. Symbolic Torque

Ancient religions [14-21] considered that symbol [2231] of Torque had magic power of universe. UFT discovered that Torque Grids unify Space, time, energy, and force. The universe is single hierarchy of Torque Grids.

\section{Topology of Nuclei}

Without knowing the structures of protons and neutrons, the topology of the nucleus is "unclear". Fortunately, an important prediction of UFT regarding nuclear structure is the shape of the proton. A nucleus is made up of protons and neutrons. Both proton and neutron share the same octahedron shape.

Octahedron protons and neutrons pile themselves up to make a nucleus. The configuration of proton/neutron octahedron pile decides the characteristics of a nucleus.

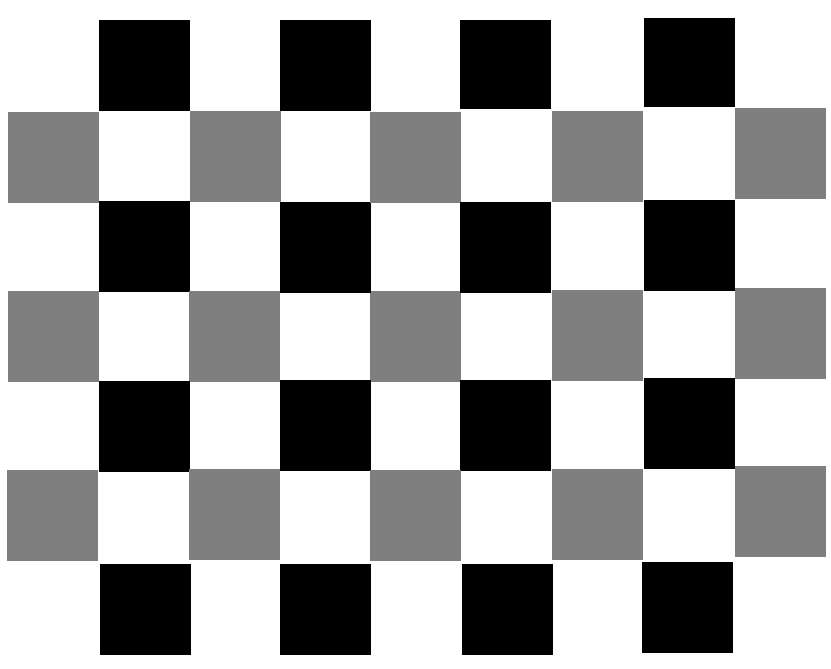

Figure 6. [31] Phosphorus

One of the important prediction of UFT is the configuration of Phosphorous. The none perfect square topology of the phosphorous gives its special crystal structure and roles in DNA [32-39] twisting: 


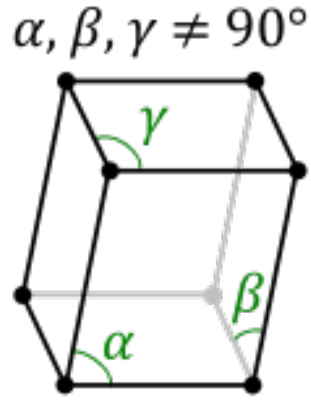

Figure 7. Phosphorous Crystal

\section{GPS and Earthquake}

The key to knowing the relative time is to understand time drift in gravity fields. The simplest way to test clock drift is to use a computer program. Even though it takes a few days to see the clock drifting pattern [4], you can test it using distributed data centers in most companies.

Clock drift tests can be conducted with a regular computer clock, while an atomic clock is needed for a commercial GPS [40-103] system. One nanosecond equals to 0.3 meter in distance, the width of a human body. As gravity introduces clock drifting, it also reduces the effectiveness of the atomic clock. Land based global time [4] proposed by UFT is an engineering solution that resolves the gravity issue and achieves two goals for GPS: accuracy improvements and cost reductions.

In addition to GPS, the precise clock drifting patterns can be used to understand the forces that move the continents. The clock in New York is faster the Chicago. According to UFT, a force is moving the continent. From equation (2), the value dt is distance between New York and Chicago divided by light speed:

$1145 / \mathrm{c}=0.00382$

Clock drifting per second is $30 \mathrm{~ns}$.

The clock drifting rate is:

\subsection{6}

Force per square meter is $0.033 \mathrm{~kg}$.

Even though the force is small, it can move the whole continent since there are weak structures on earth shell. Before earthquake, the internal earth moves gradually along the weak structures as the stronger structure resists the movements until it snaps. A sensitive atomic clock can detect clock drifting originated by the uneven earth movements introduced.

The continents are moving as follow:

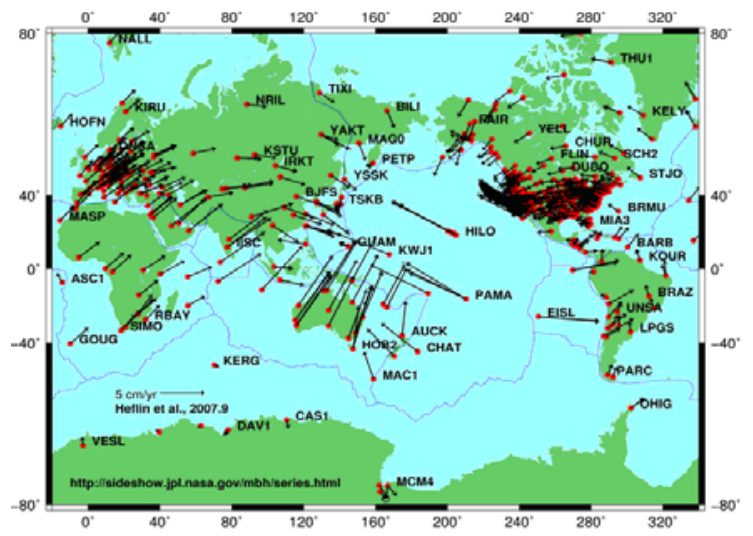

Figure 8. Continental Drifting Trend
Eventually, the continents will shift to the north and south poles as in the image below:

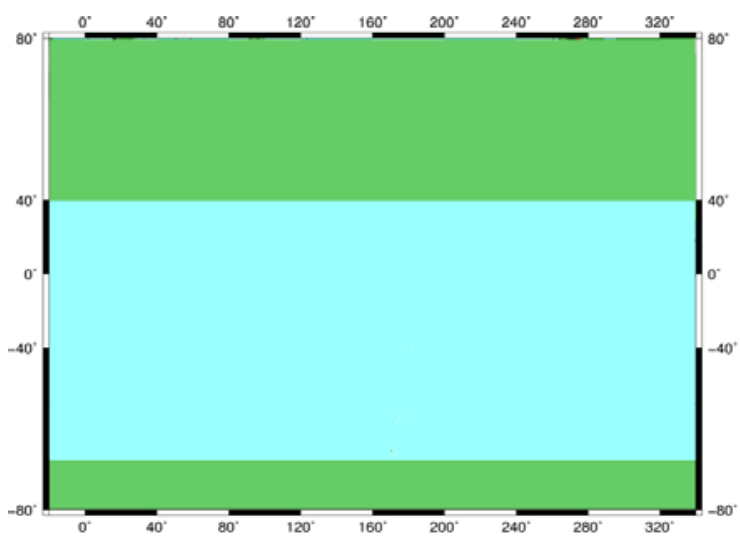

Figure 9. Final Continental Configuration

\section{Conclusion}

The universe is the unification of Space, Time, Energy and Force. The Torque model successfully derives each physics equations. Four fundamental forces can be modeled and calculated.

The mass of a particle can be expressed in a wave formula that can be used to predict the properties of the particle. The predicted octahedron proton provided the insight of nuclear topologies.

The universe is composed of hierarchical Torque Grids, meaning that the universe has always existed and will continue to exist indefinitely.

The main force behind continental drift is the gravity of the Moon. The continents will shift towards the north and south poles.

\section{References}

[1] Zhiliang Cao, Henry Gu Cao. Unified Field Theory. American Journal of Modern Physics. Vol. 2, No. 6, 2013, pp. 292-298.

[2] Cao, Zhiliang, and Henry Gu Cao. "Unified Field Theory and the Configuration of Particles.” International Journal of Physics 1.6 (2013): 151-161.

[3] Cao, Zhiliang, and Henry Gu Cao. "Unified Field Theory and the Hierarchical Universe." International Journal of Physics 1.6 (2013): 162-170.

[4] Cao, Henry Gu, and Zhiliang Cao. "Drifting Clock and Lunar Cycle.” International Journal of Physics 1.5 (2013): 121-127.

[5] Cao, Zhiliang, and Henry Gu Cao. "Unified Field Theory and Topology of Nuclei.” International Journal of Physics 2, no. 1 (2014): 15-22.

[6] Cao, Zhiliang, and Henry Gu Cao. "Non-Scattering Photon Electron Interaction.” Physics and Materials Chemistry 1, no. 2 (2013): 9-12.

[7] Cao, Zhiliang, and Henry Gu Cao. "SR Equations without Constant One-Way Speed of Light.” International Journal of Physics 1.5 (2013): 106-109.

[8] R. Oerter (2006). The Theory of Almost Everything: The Standard Model, the Unsung Triumph of Modern Physics (Kindle ed.). Penguin Group. p. 2.

[9] Sean Carroll, Ph.D., Cal Tech, 2007, The Teaching Company, Dark Matter, Dark Energy: The Dark Side of the Universe, Guidebook Part 2 page 59, Accessed Oct. 7, 2013, “...Standard Model of Particle Physics: The modern theory of elementary particles and their interactions ... It does not, strictly speaking, include gravity, although it's often convenient to include gravitons among the known particles of nature...” 
[10] In fact, there are mathematical issues regarding quantum field theories still under debate (see e.g. Landau pole), but the predictions extracted from the Standard Model by current methods applicable to current experiments are all self-consistent. For a further discussion see e.g. Chapter 25 of R. Mann (2010). An Introduction to Particle Physics and the Standard Model. CRC Press.

[11] S.L. Glashow (1961). "Partial-symmetries of weak interactions". Nuclear Physics 22 (4): 579-588. Bibcode: 1961NucPh..22..579G.

[12] S. Weinberg (1967). "A Model of Leptons". Physical Review Letters 19 (21): 1264-1266. Bibcode: 1967PhRvL..19.1264W.

[13] A. Salam (1968). N. Svartholm, ed. "Elementary Particle Physics: Relativistic Groups and Analyticity”. Eighth Nobel Symposium. Stockholm: Almquvist and Wiksell. p. 367.

[14] "The Global Religious Landscape". The Pew Forum on Religion \& Public Life. Pew Research center. 18 December 2012. Retrieved 18 March 2013.

[15] Masuzawa, Tomoko (2005). The Invention of World Religions. Chicago University of Chicago Press.

[16] Stephen R. L. Clark. "World Religions and World Orders". Religious studies 26.1 (1990).

[17] Joel E. Tishken. "Ethnic vs. Evangelical Religions: Beyond Teaching the World Religion Approach". The History Teacher 33.3 (2000).

[18] Charles Joseph Adams, Classification of religions: geographical, Encyclopedia Britannica.

[19] Brodd, Jefferey (2003). World Religions. Winona, Minnesota: Saint Mary's Press.

[20] Pippa Norris, Ronald Inglehart (2007-01-06), Sacred and Secular, Religion and Politics Worldwide, Cambridge University Press, pp. 43-44, retrieved 2006-12-29.

[21] Pew Research Center (2002-12-19). "Among Wealthy Nations U.S. Stands Alone in its Embrace of Religion”. Pew Research Center. Retrieved 2006-10-12.

[22] The Indus Script and the Rg-Veda, by Egbert Richter-Ushanas, Motilal Banarsidass Publ., 1 Jan 1997 p. 243.

[23] The Migration of Symbols, by Goblet d'Alviella, Chapter II, hosted at the Internet Sacred Text Archive

[24] The Handbook of Tibetan Buddhist Symbols, Robert Beer, Serindia Publications, Inc., 2003, p. 97.

[25] RELG: World, by Robert Van Voorst, Cengage Learning, 1 Jan 2012, p. 90.

[26] The Illustrated Encyclopedia of Hinduism: N-Z, by James G. Lochtefeld, The Rosen Publishing Group, 2002, p. 678

[27] Rosenberg, Jennifer. "History of Swastika”. about.com. Retrieved 26 April 2013.

[28] "svasti meaning". http://www.sanskritdictionary.com. Retrieved 6 June 2014.

[29] "Swastika Flag Specifications and Construction Sheet (Germany)". Flags of the World.

[30] "Centred vs. Offset Disc and Swastika 1933-1945 (Germany)". Flagspot.net. Retrieved 2 March 2010.

[31] Freed, S. A. and R. S., "Origin of the Swastika”, Natural History, January 1980, 68-75.

[32] Kabai, Sándor (2007). "Double Helix". The Wolfram Demonstrations Project.

[33] Alberts et al. (1994). The Molecular Biology of the Cell. New York: Garland Science.

[34] “Helical repeat of DNA in solution”. PNAS 76 (1): 200-203. Bibcode: 1979 PNAS...76.. 200W. PMC 382905.

[35] Pabo C, Sauer R (1984). "Protein-DNA recognition". Annu Rev Biochem 53: 293-321.

[36] James D. Watson and Francis Crick (1953). "A structure for deoxyribose nucleic acid”. Nature 171 (4356): 737-738. Bibcode: 1953 Natur. 171.. 737W.

[37] Crick F, Watson JD (1954). "The Complementary Structure of Deoxyribonucleic Acid". Proceedings of the Royal Society of London. 223, Series A: 80-96.

[38] The Structure of the DNA Molecule

[39] Wilkins MHF, Stokes AR, Wilson HR (1953). "Molecular Structure of Deoxypentose Nucleic Acids" (PDF). Nature 171 (4356): 738-740. Bibcode: 1953 Natur. 171.. 738W.

[40] National Research Council (U.S.). Committee on the Future of the Global Positioning System; National Academy of Public Administration (1995). The global positioning system: a shared national asset: recommendations for technical improvements and enhancements. National Academies Press. p. 16.
[41] "Factsheets: GPS Advanced Control Segment (OCX)". Losangeles.af.mil. October 25, 2011. Retrieved November 6, 2011.

[42] Astronautica Acta II, 25 (1956)

[43] "GPS and Relativity". Astronomy.ohio-state.edu. Retrieved November 6, 2011.

[44] Guier, William H.; Weiffenbach, George C. (1997). "Genesis of Satellite Navigation”. John Hopkins APL Technical Digest 19 (1): 178-181.

[45] Steven Johnson (2010), Where good ideas come from, the natural history of innovation, New York: Riverhead Books

[46] Helen E. Worth and Mame Warren (2009). Transit to Tomorrow. Fifty Years of Space Research at The Johns Hopkins University Applied Physics Laboratory.

[47] Catherine Alexandrow (Apr-2008). "The Story of GPS".

[48] DARPA: 50 Years of Bridging the Gap. Apr-2008.

[49] Jerry Proc. “Omega”. Jproc.ca. Retrieved December 8, 2009.

[50] “Why Did the Department of Defense Develop GPS?”. Trimble Navigation Ltd. Archived from the original on October 18, 2007. Retrieved January 13, 2010.

[51] “Charting a Course Toward Global Navigation”. The Aerospace Corporation. Retrieved January 14, 2010. [dead link]

[52] "A Guide to the Global Positioning System (GPS)-GPS Timeline". Radio Shack. Retrieved January 14, 2010.

[53] “SECOR Chronology”. Mark Wade's Encyclopedia Astronautica. Retrieved January 19, 2010.

[54] “MX Deployment Reconsidered.” Retrieved: 7 June 2013.

[55] Michael Russell Rip, James M. Hasik (2002). The Precision Revolution: GPS and the Future of Aerial Warfare. Naval Institute Press. p. 65. Retrieved January 14, 2010.

[56] “ICAO Completes Fact-Finding Investigation”. International Civil Aviation Organization. Retrieved September 15, 2008.[dead link]

[57] "United States Updates Global Positioning System Technology". America.gov. February 3, 2006.

[58] The Global Positioning System Assessing National Policies, by Scott Pace, Gerald P. Frost, Irving Lachow, David R. Frelinger, Donna Fossum, Don Wassem, Monica M. Pinto, Rand Corporation, 1995, Appendix B, GPS History, Chronology, and Budgets.

[59] "GPS \& Selective Availability Q\&A". [1]. Retrieved May 28, 2010.[dead link]

[60] “GPS Modernization Fact Sheet”. U.S. Air Force.[dead link]

[61] GPS Wing Reaches GPS III IBR Milestone in Inside GNSS November 10, 2008.

[62] “GPS almanacs”. Navcen.uscg.gov. Retrieved October 15, 2010.

[63] Dietrich Schroeer, Mirco Elena (2000). Technology Transfer Ashgate. p. 80. Retrieved May 25, 2008.

[64] Michael Russell Rip, James M. Hasik (2002). The Precision Revolution: GPS and the Future of Aerial Warfare. Naval Institute Press. Retrieved May 25, 2008.

[65] "AF Space Command Chronology". USAF Space Command. Retrieved June 20, 2011.

[66] "FactSheet: 2nd Space Operations Squadron". USAF Space Command. Retrieved June 20, 2011.

[67] The Global Positioning System: Assessing National Policies, p. 245. RAND corporation

[68] “USNO NAVSTAR Global Positioning System”. U.S. Naval Observatory. Retrieved January 7, 2011.

[69] National Archives and Records Administration. U.S. Global Positioning System Policy. March 29, 1996.

[70] "National Executive Committee for Space-Based Positioning, Navigation, and Timing”. Pnt.gov. Retrieved October 15, 2010.[dead link]

[71] “Assisted-GPS Test Calls for 3G WCDMA Networks”. 3g.co.uk. November 10, 2004. Retrieved November 24, 2010.

[72] This story was written by 010907 (September 17, 2007). “losangeles.af.mil”. losangeles.af.mil. Retrieved October 15, 2010.

[73] Johnson, Bobbie (May 19, 2009). "GPS system 'close to breakdown'“. The Guardian (London). Retrieved December 8, 2009.

[74] Coursey, David (May 21, 2009). "Air Force Responds to GPS Outage Concerns”. ABC News. Retrieved May 22, 2009.

[75] “Air Force GPS Problem: Glitch Shows How Much U.S. Military Relies On GPS”. Huffingtonpost.comm. June 1, 2010. Retrieved October 15, 2010

[76] "Contract Award for Next Generation GPS Control Segment Announced”. Retrieved December 14, 2012. 
[77] "United States Naval Observatory (USNO) GPS Constellation Status”. Retrieved October 13, 2009.

[78] United States Naval Observatory. GPS Constellation Status. Retrieved December 20, 2008.

[79] "United Launch Alliance GPS IIF-2". United Launch Alliance. Retrieved July 16, 2011.

[80] Rice University-Galileo's Theory of the Tides-by Rossella Gigli, retrieved 10 March 2010

[81] "The Laplace Tidal Equations and Atmospheric Tides".

[82] A T Doodson (1921), "The Harmonic Development of the TideGenerating Potential”, Proceedings of the Royal Society of London. Series A, Vol. 100, No. 704 (Dec. 1, 1921), pp. 305-329.

[83] S Casotto, F Biscani, "A fully analytical approach to the harmonic development of the tide-generating potential accounting for precession, nutation, and perturbations due to figure and planetary terms”, AAS Division on Dynamical Astronomy, April 2004, vol. 36 (2), 67.

[84] D E Cartwright, “Tides: a scientific history”, Cambridge University Press 2001, at pages 163-4.

[85] See e.g. T D Moyer (2003), "Formulation for observed and computed values of Deep Space Network data types for navigation”, vol. 3 in Deep-space communications and navigation series, Wiley (2003), e.g. at pp. 126-8.

[86] NOAA. "Eastport, ME Tidal Constituents". NOAA. Retrieved 2012-05-22.

[87] Tidal theory website South African Navy Hydrographic Office

[88] "Dynamic theory for tides". Oberlin.edu. Retrieved 2012-06-02.

[89] "Dynamic Theory of Tides".

[90] "Dynamic Tides-In contrast to "static" theory, the dynamic theory of tides recognizes that water covers only three-quarters 0 ". Web.vims.edu. Retrieved 2012-06-02.

[91] “The Dynamic Theory of Tides”. Coa.edu. Retrieved 2012-06-02.

[92] https://beacon.salemstate.edu/ lhanson/gls214/gls214_tides

[93] "Tides-building, river, sea, depth, oceans, effects, important, largest, system, wave, effect, marine, Pacific”. Waterencyclopedia.com. 2010-06-27. Retrieved 2012-06-02.

[94] “TIDES”. Ocean.tamu.edu. Retrieved 2012-06-02.

[95] Floor Anthoni. “Tides”. Seafriends.org.nz. Retrieved 2012-06-02.

[96] "The Cause \& Nature of Tides".

[97] “Shelf and Coastal Oceanography". Es.flinders.edu.au. Retrieved 2012-06-02.

[98] "Scientific Visualization Studio TOPEX/Poseidon images". Svs.gsfc.nasa.gov. Retrieved 2012-06-02.

[99] "TOPEX/Poseidon Western Hemisphere: Tide Height Model: NASA/Goddard Space Flight Center Scientific Visualization Studio: Free Download \& Streaming: Internet Archive". Archive.org. Retrieved 2012-06-02.

[100] http://www.geomag.us/info/Ocean/m2_CHAMP+longwave_SSH. swf

[101] "OSU Tidal Data Inversion". Volkov.oce.orst.edu. Retrieved 2012-06-02.

[102] "Dynamic and residual ocean tide analysis for improved GRACE de-aliasing (DAROTA)".

[103] Reddy, M.P.M. \& Affholder, M. (2002). Descriptive physical oceanography: State of the Art. Taylor and Francis. p. 249.

[104] Hubbard, Richard (1893). Boater's Bowditch: The Small Craft American Practical Navigator. McGraw-Hill Professional. p. 54.

[105] Coastal orientation and geometry affects the phase, direction, and amplitude of amphidromic systems, coastal Kelvin waves as well as resonant seiches in bays. In estuaries seasonal river outflows influence tidal flow.

[106] "Tidal lunar day". NOAA. Do not confuse with the astronomical lunar day on the Moon. A lunar zenith is the Moon's highest point in the sky.

[107] Mellor, George L. (1996). Introduction to physical oceanography. Springer. p. 169.

[108] Tide tables usually list mean lower low water (mllw, the 19 year average of mean lower low waters), mean higher low water (mhlw), mean lower high water (mlhw), mean higher high water (mhhw), as well as perigean tides. These are mean values in the sense that they derive from mean data."Glossary of Coastal Terminology: H-M". Washington Department of Ecology, State of Washington. Retrieved 5 April 2007.

[109] “Types and causes of tidal cycles”. U.S. National Oceanic and Atmospheric Administration (NOAA) National Ocean Service (Education section).
[110] Swerdlow, Noel M.; Neugebauer, Otto (1984). Mathematical astronomy in Copernicus's De revolutionibus, Volume 1. Springer-Verlag. p. 76.

[111] Plait, Phil (11 March 2011). “No, the “supermoon” didn’t cause the Japanese earthquake”. Discover Magazine. Retrieved 16 May 2012.

[112] Rice, Tony (4 May 2012). "Super moon looms Saturday”. WRALTV. Retrieved 5 May 2012.

[113] U.S. National Oceanic and Atmospheric Administration (NOAA) National Ocean Service (Education section), map showing world distribution of tide patterns, semi-diurnal, diurnal and mixed semidiurnal.

[114] Thurman, H.V. (1994). Introductory Oceanography (7 ed.). New York, NY: Macmillan. pp. 252-276. Ref.

[115] Ross, D.A. (1995). Introduction to Oceanography. New York, NY: HarperCollins. pp. 236-242.

[116] Le Provost, Christian (1991). Generation of Overtides and compound tides (review). In Parker, Bruce B. (ed.) Tidal Hydrodynamics. John Wiley and Sons.

[117] Accad, Y. \& Pekeris, C.L. (November 28, 1978). "Solution of the Tidal Equations for the M2 and S2 Tides in the World Oceans from a Knowledge of the Tidal Potential Alone”. Philosophical Transactions of the Royal Society of London. Series A, Mathematical and Physical Sciences 290 (1368): 235-266.

[118] "Tide forecasts". New Zealand: National Institute of Water \& Atmospheric Research. Retrieved 2008-11-07. Including animations of the M2, S2 and K1 tides for New Zealand.

[119] Schureman, Paul (1971). Manual of harmonic analysis and prediction of tides. U.S. Coast and geodetic survey. p. 204.

[120] Lisitzin, E. (1974). "2 "Periodical sea-level changes: Astronomical tides”“'. Sea-Level Changes, (Elsevier Oceanography Series) 8. p. 5.

[121] “What Causes Tides?”. U.S. National Oceanic and Atmospheric Administration (NOAA) National Ocean Service (Education section).

[122] See for example, in the 'Principia' (Book 1) (1729 translation), Corollaries 19 and 20 to Proposition 66, on pages 251-254, referring back to page 234 et seq.; and in Book 3 Propositions 24, 36 and 37, starting on page 255.

[123] Wahr, J. (1995). Earth Tides in "Global Earth Physics”, American Geophysical Union Reference Shelf \#1,. pp. 40-46.

[124] Zuosheng, Y.; Emery, K.O. \& Yui, X. (July 1989). "Historical Development and Use of Thousand-Year-Old Tide-Prediction Tables”. Limnology and Oceanography 34 (5): 953-957.

[125] Cartwright, David E. (1999). Tides: A Scientific History. Cambridge, UK: Cambridge University Press.

[126] Case, James (March 2000). "Understanding Tides—From Ancient Beliefs to Present-day Solutions to the Laplace Equations”. SIAM News 33 (2).

[127] Doodson, A.T. (December, 1921). "The Harmonic Development of the Tide-Generating Potential". Proceedings of the Royal Society of London. Series A 100 (704): 305-329. Bibcode: 1921RSPSA.100..305D.

[128] Casotto, S. \& Biscani, F. (April 2004). "A fully analytical approach to the harmonic development of the tide-generating potential accounting for precession, nutation, and perturbations due to figure and planetary terms". AAS Division on Dynamical Astronomy 36 (2): 67.

[129] Moyer, T.D. (2003) "Formulation for observed and computed values of Deep Space Network data types for navigation”, vol. 3 in Deep-space communications and navigation series, Wiley, pp. 126-8.

[130] According to NASA the lunar tidal force is 2.21 times larger than the solar.

[131] See Tidal force-Mathematical treatment and sources cited there.

[132] Munk, W.; Wunsch, C. (1998). "Abyssal recipes II: energetics of tidal and wind mixing”. Deep Sea Research Part I Oceanographic Research Papers 45 (12): 1977. Bibcode: 1998DSRI...45.1977M.

[133] Ray, R.D.; Eanes, R.J.; Chao, B.F. (1996). "Detection of tidal dissipation in the solid Earth by satellite tracking and altimetry". Nature 381 (6583): 595. Bibcode: 1996Natur.381..595R.

[134] Lecture 2: The Role of Tidal Dissipation and the Laplace Tidal Equations by Myrl Hendershott. GFD Proceedings Volume, 2004, WHOI Notes by Yaron Toledo and Marshall Ward.

[135] Flussi e riflussi. Milano: Feltrinelli. 2003.

[136] van der Waerden, B.L. (1987). "The Heliocentric System in Greek, Persian and Hindu Astronomy”. Annals of the New York 
Academy of Sciences 500 (1): 525-545 [527]. Bibcode: 1987NYASA.500..525V.

[137] Cartwright, D.E. (1999). Tides, A Scientific History: 11, 18

[138] "The Doodson-Légé Tide Predicting Machine”. Proudman Oceanographic Laboratory. Retrieved 2008-10-03.

[139] Glossary of Meteorology American Meteorological Society.
[140] Webster, Thomas (1837). The elements of physics. Printed for Scott, Webster, and Geary. p. 168.

[141] "FAQ”. Retrieved June 23, 2007.

[142] O'Reilly, C.T.R.; Ron Solvason and Christian Solomon (2005). "Where are the World's Largest Tides". In Ryan, J. BIO Annual Report "2004 in Review" (in English) (Washington, D.C.: Biotechnol. Ind. Org.): 44-46. 